Sumário: 1 Introdução; 2 História: conceitos e alguns apontamentos; 3 Direito: conceitos e alguns apontamentos; 4 História do Direito: conceito e convergências de duas áreas do conhecimento; 5 Considerações finais.

Resumo: O presente trabalho procura relacionar duas áreas do saber, quais sejam a História e o Direito. Dessa relação nasce uma terceira: a História do Direito. Aqui, buscar-se-ão os conceitos de ambas, além de fazerem-se alguns outros apontamentos. Com base em REFERÊNCIAS bibliográficas que dizem respeito ao tema, procurou-se entender melhor como funciona a disciplina derivada: a História Jurídica. De modo a cumprir tais objetivos, tentar-se-á buscar seu conceito, bem como seus objetivos e sua razão de existir, além de perceber como as transformações da sociedade influenciam as duas áreas em questão.

Palavras-chave: História. Direito. História do Direito.

* Doutor em História pela Universidade de São Paulo - USP. É professor do Departamento de História da Universidade Estadual de Montes Claros, atuando na Graduação e no Programa de Pós-graduação em História (PPGH) da Unimontes (e-mail: alfluiz@yahoo.com.br).

* Graduado em História pela Universidade Estadual de Montes Claros (Unimontes) e Bacharelando em Direito pela Faculdade de Direito Santo Agostinho (FADISA) (e-mail: renatnureyev@yahoo. com.br). 


\section{Introdução}

A fim de melhor compreender a História do Direito, entendendo, assim, os diálogos entre essas duas áreas do saber, tentar-se-á responder a algumas questões fundamentais para tal intuito, quais sejam: O que é História? O que é Direito? O que é História do Direito? Quais pontos História e Direito têm em comum? Qual é o objetivo do estudo da História do Direito?

Satisfeitas tais questões, haverá naturalmente uma simplificação do estudo do objeto a ser abordado pelos jus-historiadores. Nesse sentido, "essa necessidade do conhecimento do objeto antes de uma análise de seus pontos é a base para a compreensão global do objeto de estudo de qualquer ciência" (CASTRO, 2009, p. 1).

Para alcançar os escopos pretendidos, dividiu-se o trabalho de uma maneira didática, de modo a facilitar a leitura dos interessados. Primeiramente, buscou-se tratar da História, conceituando-a e fazendo alguns outros apontamentos. Em um segundo momento, tentou-se conceituar, outrossim, o Direito, e fazer algumas observações importantes. Por fim, houve uma tentativa de se relacionar essas duas áreas do saber que, por vezes, "andam de mãos dadas"; aqui, tentar-se-á buscar o conceito de História do Direito, bem como seus objetivos e os pontos em comum entre as duas áreas do saber.

\section{História: conceitos e alguns apontamentos}

Passado é a primeira palavra que vem à mente quando se pensa em História. Crucial, nesse sentido, torna-se pensar se o passado seria história; se todo o passado seria história; e, por fim, se tudo no passado seria história (CASTRO, 2009). Acredita-se que todo o passado poderia ser história e que, desse modo, tudo nele também poderia sê-lo. ${ }^{1}$ Todavia, há alguns elementos que devem ser levados em consideração - e é justamente sobre eles que se tratará neste primeiro tópico.

Vavy Pacheco Borges busca o conceito de história no dicionário, onde encontra algumas definições. Dentre elas, elenca quatro ou cinco, dando especial destaque a duas, que julga mais apropriadas para o que busca um historiador. Nesse sentido, segundo a autora:

\footnotetext{
1 Sob uma nova ótica da História, o que se percebe é que surge uma variedade de objetos possíveis de serem estudados; nesse sentido, não só grandes feitos, grandes heróis, ou as nações mais “importantes" têm história, mas todos e tudo também a têm.
} 
No novo dicionário Aurélio, ao se procurar o termo "história" encontramos muitos significados para a palavra. Entre uns quinze enumerados, podemos destacar alguns que enfocam a história como: o passado da humanidade, o estudo desse mesmo passado, uma simples narração, uma "lorota", uma complicação, etc. Todos esses conceitos podem ser vistos como relacionados ao conceito atual de história. (BORGES, 1993, p. 47)

Neste trabalho, entretanto, utilizar-se-ão os dois primeiros conceitos elencados pela referida autora. Borges (1993) destaca que, na língua portuguesa, usa-se um mesmo termo para significar, ao mesmo tempo, dois sentidos diferentes. ${ }^{2}$ Nesse diapasão, o termo história significa, simultaneamente, os acontecimentos que se passaram e o estudo desses acontecimentos (BORGES, 1993). "Numa extensão ampla dos dois sentidos, história seria então aquilo que aconteceu [principalmente com o homem] e o estudo desses acontecimentos" (BORGES, 1993, p. 48). Destarte, percebe-se que as duas definições da palavra estão intimamente ligadas: os acontecimentos históricos são o objeto de estudo do conhecimento histórico.

Ehrarde e Palmade dizem que "a história é a memória da humanidade, mas não é suficiente recordar para ser historiador" (EHRARDE; PALMADE apud CASTRO, 2009, p. 1); eis o porquê de alguns historiadores diferenciarem o trabalho de sua "classe" do trabalho dos memorialistas. Segundo esse pensamento, os historiadores constroem um trabalho com uma visão crítica, buscando algo diferenciado, enquanto os memorialistas apenas reproduzem fatos ocorridos no passado, registrandoos. Assim, percebe-se que é demasiado importante buscar uma ótica crítica nos trabalhos desenvolvidos na ciência histórica, visto que o vernáculo "crítica" tem de estar na definição da história e, por conseguinte, do historiador.

Já se falou, nessa oportunidade, de passado e de visão crítica. A essas duas expressões, que deveriam fazer parte do conceito de história, podese, outrossim, adicionar outras duas, quais sejam: transformação e fator humano. Aquela, por ser a essência da história e, este, o ser humano, por ser o único capaz de executar tal tarefa (CASTRO, 2009). Assim, pode-se chegar à conclusão de que o homem é o objeto da História, ou seja, "o estudo da História concentra-se no Ser Humano e na sucessão temporal de seus atos" (CASTRO, 2009, p. 2). Deste modo, "a história é a história

\footnotetext{
2 Diferentemente do que acontece em outras línguas, como, por exemplo, no alemão, em que existe mais de um termo para se explicar duas coisas diferentes, no português usa-se uma palavra para vários significados (BORGES, 1993).
} 
do homem, visto como um ser social, vivendo em sociedade. É a história das transformações humanas, desde o seu aparecimento na terra até os dias em que estamos vivendo" (BORGES, 1993, p. 48).

Para Albergaria (2012), os seres humanos são, simultaneamente, atores e observadores da história. Eles têm consciência, ou seja, sabem da importância dos fatos em suas vidas e, munidos desse conhecimento, tentam modificar tudo aquilo que não lhes agrada ou que simplesmente pode ser melhorado (ALBERGARIA, 2012), o que demonstra a importância da História.

Paul Veyne entende que há uma tentativa de explicação do ser humano a partir do estudo de sua própria espécie. Segundo ele, há dois motivos para isso:

Primeiramente, o fato de pertencermos a grupo nacional, familiar [...] pode fazer com que o passado desse grupo tenha um atrativo particular para nós [seres humanos pertencentes a esse grupo]; a segunda razão é a curiosidade, seja anedótica ou acompanhada de uma exigência da inteligibilidade. (VEYNE, 1998, p. 69)

Assim, na tentativa de criação de um conceito para a história, levando em consideração tudo o que foi tratado na primeira parte deste trabalho, chegou-se ao seguinte: História é o passado da humanidade, bem como seu estudo, normalmente feito pelos historiadores, com uma visão crítica, levando-se em consideração as transformações ocasionadas pelo homem na sociedade, com seus atos, ao longo do tempo.

Sabe-se, agora, o que é a História; mas para que ela serve? É de Vavy Pacheco a resposta: “A função da História, desde seu início, foi a de fornecer à sociedade uma explicação sobre ela mesma" (BORGES, 1993, p. 49). Dessa maneira, "saber o que o homem fez em sociedade desde que está na Terra mostra muito sobre o próprio homem, ajuda a entendê-lo e a entender as sociedades, é como o fato de se saber o que faz e fez uma pessoa, ajuda a entendê-la" (BORGES, 1993, p. 54).

Ainda sobre a importância e a função da História, Albergaria (2012) leciona que para que o ser humano possa entender quem é, como pensa e como sente, é necessário que se tenha consciência de sua história, de seu passado. Para ele, deve-se aprender, com a História, o que o homem já fez e deu certo, para repetir, bem como perceber o que deu errado para tentar evitar esses erros (ALBERGARIA, 2012). Só quem conhece a história consegue entender seu sentido e utilizá-la como ferramenta para melhorar o presente e, quem sabe, antever um pouco o futuro (ALBERGARIA, 2012). 
A fim de fornecer uma explicação à sociedade sobre si mesma e tentar repetir acertos e evitar erros, a História, atualmente, aproxima-se cada vez mais das outras áreas do conhecimento que estudam o homem (Sociologia, Antropologia, Economia, Geografia, Psicologia, Demografia etc.).

A estas áreas do conhecimento, elencadas no parágrafo anterior, adiciona-se, nessas linhas, o Direito. Este sempre tem ajudado a História a dar algumas explicações para a sociedade. Muitas vezes ele serve de fonte para a História, e, em outras oportunidades, busca na História respostas para questões atuais; entretanto, sobre a relação entre os dois, tratar-se-á adiante.

\section{Direito: conceitos e alguns apontamentos}

Sobre a origem do termo Direito, Flávia Lages de Castro discorre:

A palavra "Direito", bem como ele próprio no sentido amplo da Ciência do Direito, vem dos romanos antigos e é a soma da palavra dis (muito) + rectum (reto, justo, certo), ou seja, Direito em sua origem significa o que é muito justo, o que tem justiça (CASTRO, 2009, p. 2).

Sabendo, portanto, que a palavra direito formou-se dessa junção latina (dis + rectum), pode-se entendê-la, segundo um verbete de De Plácido e Silva, como "tudo aquilo que é conforme a razão, a justiça e a equidade" (apud NASCIMENTO, 2001, p. 7).

Nos dizeres do mestre Miguel Reale, "a palavra Direito tem diferentes acepções, o que pode parecer estranho, mas já advertimos que é impossível nas ciências humanas ter-se sempre uma só palavra para indicar determinada ideia e apenas ela" (REALE, 2011, p. 64). Não se pode negar a verdade do comentário do Professor Reale, todavia, pode-se acrescentar que, não obstante a palavra direito apresente-se com uma diversidade de acepções, e cada uma com suas peculiaridades, elas se inter-relacionam.

Sobre essa questão, discutida no parágrafo acima, o Professor Waldir de Pinho Veloso comenta detalhadamente. Segundo esse autor:

$\mathrm{O}$ vocábulo direito pertence à classe das palavras analógicas ${ }^{3}$ - aquelas que têm sentidos diferentes, mas com ligação, conexão, entre si. Assim, se diz-se que Direito é uma lei, uma norma, há uma classificação de tal ciência com objetividade. Para se entender Direito em sentido subjetivo, tem-se de

Assim como a História, como pôde ser visto no tópico anterior, o Direito também é uma palavra analógica (sentidos diferentes, mas com ligação entre si). 
entendê-lo como uma possibilidade de dispor do que pertence a alguém ou como concessão de uma atitude a outrem na área que é particular a alguém, e, se pensa-se o direito como aquilo que é correto, reto, perfeito, a qualidade justiça é que vale mais. Como palavra analógica, pode-se perceber que tanto o caráter objetivo quanto o subjetivo ou na questão da qualidade, o que se fala em direito tem ligação entre si. Há, portanto, conexão de ideias, embora com significados diferentes (VELOSO, 2005, p. 22).

Apesar de parecer simples dar uma definição para o Direito, essa é uma tarefa demasiado complexa. Nesse sentido, o Direito pode ser definido, assim como a História, de diversas maneiras. Semanticamente, "o vocábulo direito é polissêmico, por ter mais de um significado para um único verbete" (VELOSO, 2005, p. 22). Dessa forma, Direito pode ser um curso superior que forma bacharéis; pode ser, ainda, o ordenamento jurídico de um país (Direito brasileiro, Direito argentino, alemão, etc.); pode, outrossim, ser um direito subjetivo de alguém; pode ser utilizado como sinônimo de justiça, como fato social, entre outras possibilidades. Sendo assim, a palavra direito pode apresentar múltiplas acepções.

Seguindo esse raciocínio, Dimitri Dimoulis (2008) distingue quatro significados diferentes para o termo direito. No primeiro, ele escreve que "Direito é o justo, aquilo que cada pessoa deve fazer ou deixar de fazer em uma sociedade bem ordenada e justa. Esse significado está relacionado com o termo latino directum, que significa reto, bem direcionado, correto" (DIMOULIS, 2008, p. 18-19). No segundo significado para o termo, ele diz que "Direito é aquilo que alguém pode fazer, exercendo uma faculdade [...], exigindo uma prestação [...] ou omissão [...]. Essa é definição do 'direito subjetivo"” (DIMOULIS, 2008, p. 19) - daí a ideia da facultas agendi. Em outra definição, Dimoulis registra: "Direito é o estudo das normas jurídicas [...]. Aqui, o termo 'direito' designa o conjunto das disciplinas jurídicas, que muitos denominam 'ciências jurídicas"” (DIMOULIS, 2008, p. 19).

Em uma última tentativa de mostrar mais uma definição dada ao Direito, Dimoulis ensina que este "é o conjunto de normas que objetiva regulamentar o comportamento das pessoas na sociedade. Essas normas são editadas pelas autoridades competentes e preveem, em caso de violação, a imposição de penalidades por órgãos do Estado" (DIMOULIS, 2008, p. 19) - eis a ideia da normas agendi.

Leid Soibelman, com o brilhantismo que lhe é peculiar, preleciona que:

Existem dezenas de definições do Direito, e Kant admitiu que não havia uma definição que satisfizesse a todos. É que a definição exige um estudo prévio 
para separar o direito das normas de outra natureza que regem a vida humana, tais como as regras morais, a de adesão a uma filosofia que conceitua o jurídico desta ou daquela forma, por antecipação ao conjunto com a realidade que deverá ser reconhecida como jurídica (SOIBELMAN apud VELOSO, 2005, p. 23).

Concorda-se, por evidente, com Soibelman, quando ele enfatiza a dificuldade em se definir o Direito. Já se mostrou, nos parágrafos acima, o caráter analógico e polissêmico do Direito. Cabe, ainda, ressaltar, nessa oportunidade, que o conceito de direito sofre mudanças ao longo dos tempos. Dimitri Dimoulis elenca dezoito definições do Direito na "Lição 1" de seu livro Manual de introdução ao estudo do Direito, mostrando exatamente essa ideia de diferença entre os conceitos. Em sua busca pelo conceito de Direito, o autor destaca uma série de autores, são eles: Platão, Aristóteles, os Estoicos, Celso e Ulpiano, Tomás de Aquino, Thomas Hobbes, Samuel Pufendorf, Baruch Spinoza, Jean-Jacques Rousseau, Immanuel Kant, Georg Wilhelm Friedrich Hegel, Friedrich Carl von Savigny, Karl Magnus Bergbohm, Eugen Ehrlich, Hans Kelsen, Yevgeniy Bronislavovich Pachukanis, Robert Alexy e Eros Roberto Grau.

Pensando nas convergências das definições dos pensadores elencados acima, Dimoulis (2008) percebe que os pontos em comum nesses conceitos são a relatividade histórica do Direito, o Direito como dever ser social e a coerção. Esses são elementos presentes nas definições dos autores citados, feitas em diversos períodos históricos.

Sobre a relatividade histórica do Direito, Dimoulis (2008) afirma que a definição do Direito não pode ser válida para todas as sociedades e para todos os tempos. Nesse sentido, fica evidente o dinamismo do Direito. Como exemplo disso, têm-se as palavras, também de Dimitri Dimoulis: "O direito que conhecia Platão ou Aristóteles era diferente do direito cristão da época medieval e este último é diferente do direito capitalista da atualidade" (DIMOULIS, 2008, p. 35).

Em todas as definições, os autores dos conceitos de Direito consentem que ele é composto de normas que regulamentam o comportamento das pessoas na sociedade, mostrando, assim, a característica do dever ser social do Direito. Por fim, "um outro elemento em comum das várias definições encontra-se na constatação de que o direito é um dever ser de particular natureza [...] um dever ser particularmente forte e ameaçador" (DIMOULIS, 2008, p. 38), o que demostra a presença do elemento "coerção" nos conceitos de Direito.

Refletindo um pouco sobre as divergências ideológicas nas definições de direito, Dimoulis comenta que "esses elementos em comum não 
escondem as grandes divergências entre as definições do direito. Quando se trata de autores que viveram em épocas diferentes, podemos explicar as diferenças lembrando da relatividade histórica das experiências jurídicas" (DIMOULIS, 2008, p. 38). Todavia, quando os autores atuaram no mesmo período e contexto, às vezes até na mesma cultura, e ainda assim apresentam definições distintas do direito, para Dimoulis, essa divergência deve-se "ao fato de que cada um adota uma ótica diferente, devido às suas concepções filosóficas e científicas” (DIMOULIS, 2008, p. 39), como já explicou Soibelman em palavras acima.

Pensando o Direito em qualquer uma de suas definições, mas observando, principalmente, a última definição feita por Dimoulis, entendendo o Direito, em um sentido comum, como "o conjunto de normas para a aplicação da justiça e a minimização de conflitos de uma dada sociedade" (CASTRO, 2009, p. 2), pode-se perceber o fator humano. Tanto é que, para Castro, "estas normas, estas regras, esta sociedade [presentes no conceito acima] não são possíveis sem o Homem, porque é o Ser Humano quem faz o Direito e é para ele que o Direito é feito" (CASTRO, 2009, p. 2). Aqui, percebe-se o quão importante é o indivíduo na confecção do Direito e a quem este se destina.

Vicente Ráo comenta sobre essa dependência do fator humano. Segundo ele, "o direito pressupõe, necessariamente, a existência daquele ser e daquela atividade. Tanto vale dizer que pressupõe a coexistência social, que é o próprio homem" (RÁO, 1995, p. 51). Nesse mesmo diapasão, Maria Helena Diniz ensina que:

O ser humano é gregário por natureza, não só pelo instinto sociável, mas também por força de sua inteligência, que lhe demonstra que é melhor viver em sociedade para atingir seus objetivos. O homem é "essencialmente coexistência", pois não existe apenas, mas coexiste, isto é, vive necessariamente em companhia de outros indivíduos. Com isso, espontânea e até inconscientemente, é levado a formar grupos sociais: família, escola, associações esportiva, recreativa, cultural, religiosa, profissional, sociedades agrícola, mercantil, industrial, grêmio, partido político, etc. (DINIZ, 2012, p. 260).

Nesse sentido, frente às reflexões apresentadas sobre a História e o Direito enquanto ciências, fica evidente a importância das duas áreas, bem como uma clara relação delas com o homem. Não se faz História ou Direito sem se perceber as constantes transformações da sociedade e os mecanismos tradicionais e legais que conformam as relações sociais. História e Direito, nesse contexto, inter-relacionam-se, permitindo a compreensão mais eficiente de uma História do Direito. 


\section{História do Direito: conceito e convergências de duas áreas do conhecimento}

Ricardo David Rabinovich-Berkman (2011) entende que existem duas áreas do saber presentes na História do Direito, todavia, mesmo sendo um jurista, por suas palavras, não desvalorizando o Direito (logicamente), percebe-se uma exaltação da História. Para ele, quando se diz História do Direito, faz-se referência a duas ciências: a histórica e a jurídica. Dessa forma, assumir-se-ia como proposta a existência de uma terceira disciplina. Esta teria suas peculiaridades, mas sempre seria uma ciência histórica. Ainda sobre essa questão, Rabinovich-Berkman esclarece que:

$\mathrm{O}$ fato de tratar-se de uma disciplina histórica significaria que as pessoas que a cultiva buscam pesquisar, descobrir e recriar o passado humano. $\mathrm{O}$ fato de ser "jurídica" implicaria que elas se interessariam especificamente pelos aspectos do passado vinculados ao direito de modo mediato ou imediato (RABINOVICH-BERKMAN, 2011, p. 1).

Destarte, quem optar por trabalhar com essa disciplina, História do Direito, deverá utilizar as ferramentas críticas e as categorias terminológicas de ambas as disciplinas: a História e o Direito (RABINOVICHBERKMAN, 2011).

Ao contrário do que prega Rabinovich-Berkman, Bruno Albergaria valoriza o Direito no que diz respeito a essa relação História-Direito, e, assim, ele acusa, tempestivamente, sobre a importância da História do Direito e seu papel sine qua non para se entender a sociedade e a humanidade. Para ele,

é importante destacar que o Direito é a própria História da nossa humanidade. Não há como separar os dois elementos. Apesar de a História poder ser vista por várias facetas, tais como pelas artes, pela culinária, pela filosofia, pela medicina, pelo desenvolvimento científico e tecnológico, é justamente pela noção jurídica dos povos que se tem uma correta interpretação do mundo pretérito e de cada cultura (ALBERGARIA, 2012, p. 4).

Dessa forma, percebe-se que "a história do Homemé, indefectivelmente, uma História do mundo jurídico, isto é, uma História do Direito" (ALBERGARIA, 2012, p. 4). Nesse sentido, "o objetivo da história do direito é a interpretação dialética do fenômeno jurídico e seu dimensionamento em função do tempo" (DINIZ, 2012, p. 249).

No livro História do Direito no Brasil, Antônio Carlos Wolkmer, um dos maiores jus-historiadores do Brasil, considerados por muitos o maior, disserta que pode, ademais, 
conceituar a História do Direito como parte da História geral que examina o Direito como fenômeno sócio-cultural, inserido num contexto fático, produzido dialeticamente pela interação humana através dos tempos, e materializado evolutivamente por fontes históricas, documentos jurídicos, agentes operantes e instituições legais reguladoras (WOLKMER, 2010, p. 5).

Nesse ínterim, pode-se dizer que "a história do direito estuda as instituições jurídicas dos povos civilizados nas fases sucessivas de seu desenvolvimento. Baseia-se em documentos, representados por escritos ou por monumentos chegados até nós, como o Código de Hamurabi, de mais ou menos 2000 a.C." (KLABIN, 2004, p. 21).

É interessante destacar, ainda, que o "direito não se conserva estático, mas se dinamiza e se transforma na medida em que as condições sociais assim exigem; não há como desvinculá-lo da realidade histórica, pois é preciso saber como este direito foi, até ontem, para entendê-lo, hoje, e melhorá-lo, amanhã" (AZEVEDO, 2005, p. 21). Assim,

o historiador procura reviver ou reconstruir o fenômeno jurídico em sua singularidade específica a fim de compreender seu significado no tempo. Faz uma análise atual do direito pretérito para, verificando os fins que perseguiram e seus efeitos sobre a sociedade, assinalar as vantagens ou inconvenientes das normas ou instituições no passado, comparando as soluções que se deram antes ou surgiram depois, para chegar ao conhecimento de todo processo histórico do direito (DINIZ, 2012, p. 248-249).

Sabe-se que, para se fazer História do Direito, é preciso pesquisar as legislações da época, mas, só as leis são suficientes como fontes para esse tipo de pesquisa? Aracy Augusta Leme Klabin responde:

As fontes da história do direito, além dos escritos propriamente jurídicos, tais como leis e obras dos jurisconsultos, utilizam também documentos de ordem histórica e literária. A "história romana" de Tito Lívio; os discursos tratados de Cícero, por exemplo, completam o manancial de documentos nos quais se abebera o historiador do direito romano (KLABIN, 2004, p. 22).

Pensando na finalidade de se estudar História do Direito, Wolkmer (2010) leciona que, quanto aos objetivos da História do Direito, o escopo é fazer compreender como é que o Direito atual formou-se e desenvolveuse, bem como de que maneira evoluiu no correr dos séculos. Do mesmo modo, o intuito é o exame crítico das legislações passadas, com a finalidade de exposição de suas sucessivas transformações, frisando, com efeito, os modos por que estas ocorreram, conforme as mudanças da consciência, das condições e necessidades sociais. Em resumo, 
a finalidade essencial da História do Direito é a interpretação critico-dialética da formação e da evolução das fontes, ideias norteadoras, formas técnicas e instituições jurídicas, primando pela transformação presente do conteúdo legal instituído e buscando nova compreensão historicista do Direito num sentido social e humanizador (WOLKMER, 2010, p. 6).

Conhece-se, agora, a importância da História do Direito, seu conceito, seu objeto e sua finalidade. Assim, para se complementar esse tópico, pretende-se relacionar, de maneira mais detalhada, a História e o Direito. Nesse sentido, além de serem palavras em que ambas têm caráter polissêmico e analógico, como já tratado, é "possível perceber que História e Direito têm [ainda] algo em comum: o Homem. Assim, partindo do Ser Humano, é necessário salientar alguns pontos primordiais" (CASTRO, 2009, p. 3).

Castro entende que "o homem é naturalmente produtor de cultura. Não somente aquilo que chamam comumente de cultura, como saber sobre autores clássicos, vinhos caros e literatos, mas a cultura no sentido correto da palavra" (CASTRO, 2009, p. 3-4). Destarte, é interessante recordar algumas formulações convencionais de cultura. Cumpre assinalar que esta pode expressar "a totalidade das manifestações e formas de vida que caracterizam um povo" (JAEGER, 1979, p. 7); "o conjunto de tudo aquilo que, nos planos material e espiritual, o homem constrói sobre a base da natureza, quer para modificá-la, quer para modificar-se a si mesmo" (REALE, 2011, p. 25); e, ainda, que "cultura é o conjunto das práticas, das técnicas, dos símbolos e dos valores que se devem transmitir às novas gerações para garantir a reprodução de um estado de coexistência social" (BOSI, 1992, p. 16).

Tais conceitos vão pelo mesmo caminho; todos têm o mesmo sentido. Dessa forma, há convergências nos conceitos, pois, Jaeger, Reale e Bosi visualizam a cultura como "o processo pelo qual o homem acumula as experiências que vai sendo capaz de realizar, discerne entre elas, fixa as de efeito favorável e, como resultado da ação exercida, converte em ideias as imagens e lembranças" (PINTO apud CASTRO, 2009, p. 4).

Pode-se, portanto, perceber que "a cultura é temporal, histórica. Ela depende do momento em que determinado indivíduo ou comunidade estão vivendo para ter as características que a definem" (CASTRO, 2009, p. 4). Para confirmar isso, tem-se o ditado árabe citado pelo historiador Marc Bloch, que diz: "O Homem se parece mais com seu tempo que com seus pais" (BLOCH, 1976, p. 36). 
Nesse diapasão, pode-se concluir que:

Sendo o Direito uma produção humana, ele também é cultura e é produto do tempo histórico no qual a sociedade que o produziu ou produz está inserida. Plagiando o ditado árabe, poderíamos afirmar que o direito se parece com a necessidade histórica da sociedade que o produziu; é, portanto, uma produção cultural e um reflexo das exigências desta sociedade (CASTRO, 2009, p. 4).

Compartilhando desse pensamento, Jayme de Altavila (1963, p. 8) escreve que "os direitos sempre foram espelhos das épocas". Para ele,

os direitos dos povos equivalem precisamente ao seu tempo e explicam no espaço de sua gestação. Absurdos, dogmáticos, rígidos, lúdicos e liberais, foram, todavia, os anseios, as conquistas e os baluartes de milhões de seres que, para eles, levantaram as mãos, em gesto de súplica ou de enternecido reconhecimento (ALTAVILA, 1963, p. 12).

\section{Considerações finais}

Acredita-se que um maior diálogo entre a História e o Direito contribuiria para um maior avanço dessas duas áreas do saber. Com efeito, o Direito serviria como campo (ou como fonte) de pesquisa para a História. Já esta poderia ser útil para o melhor entendimento daquele.

Ainda pensando na relação entre as já supracitadas áreas do saber, "a história se mostra importante para o Direito no momento em que serve como conhecimento e acúmulo de experiências passadas, possibilitando uma ampliação das análises de situações jurídicas e na interpretação dos textos normativos" (FERREIRA, 2008, p.1). A recíproca é verdadeira. A História, outrossim, precisa do Direito; este, segundo Bruno Albergaria (2012, p. 4), em citação já esplanada aqui, propicia à História "uma correta interpretação do mundo pretérito e de cada cultura". Portanto, a noção jurídica da história permite que se compreenda melhor a cultura, a sociedade, a política e o sistema de um determinado povo.

Mesmo assim, um importante aspecto deve ser reafirmado quando se procuram interseções entre duas áreas: não se faz História sem compreender o homem. Não existe Direito sem a importante consideração quanto aos atos do indivíduo em sociedade. Logo, a História jurídica só se legitimará a partir da exata compreensão das transformações sociais que alteraram a visão do homem sobre a História e sobre o Direito. 


\section{Dialogue between History and Law: concepts, convergences and other issues}

Abstract: This paper aims to relate two disciplines, namely History and Law. From this relationship rises a third: the History of Law. It will delineate the concepts of both disciplines, in addition to a few other notes. Based on references related to the theme, we sought to better understand how the derived discipline works: The Legal History. Thus, in order to accomplish these objectives, will try to out-get its concept, as well as their purpose and their reason for being, and try to understand how the changes in society influence the two areas in question.

Keywords: History. Law. History of Law.

\section{REFERÊNCIAS}

ALBERGARIA, Bruno. Histórias do Direito: evolução das leis, fatos e pensamentos. 2. ed. São Paulo: Atlas, 2012.

ALTAVILA, Jayme de. Origem dos direitos dos povos. 3. ed. São Paulo: Edições Melhoramentos, 1963.

BLOCH, Marc. Introdução à História. Sintra: Europa-América 1976.

BORGES, Vavy Pacheco. O que é História. São Paulo: Brasiliense, 1993.

BOSI, Alfredo. Dialética da colonização. São Paulo: Companhia das Letras, 1992.

CASTRO, Flávia Lages de. História do Direito: geral e do Brasil. Rio de Janeiro: Lumen Juris, 2009.

DIMOULIS, Dimitri. Manual de introdução ao estudo do Direito.

São Paulo: Editora Revista dos Tribunais, 2008.

DINIZ, Maria Helena. Compêndio de introdução à ciência do Direito: Introdução à Teoria geral do Direito, à Filosofia do Direito, à Sociologia Jurídica. São Paulo: Saraiva, 2012. 
FERREIRA, Eduardo Oliveira. A importância da História para o Direito. Disponível em: $<$ http://cacyrodosanjos.files.wordpress.com>. Acesso em: 12 dez. 2013.

KLABIN, Aracy Augusta Leme. História geral do Direito. São Paulo: Revista dos Tribunais, 2004.

JAEGER, Werner. Paidéia: a formação do homem grego. São Paulo: Martins Fontes, 1979.

LOPES, José Reinaldo de Lima. O Direito na história: lições introdutórias. São Paulo: Max Limonad, 2000.

NASCIMENTO, Walter Vieira do. Lições de História do Direito. Rio de Janeiro: Forense, 2001.

PINHEIRO, Ralph Lopes. História resumida do Direito. 11. ed. Rio de Janeiro: Thex Ed, 2004.

RABINOVICH-BERKMAN, Ricardo David. Trilhas abertas na História do Direito: conceitos, metodologia, problemas e desafios. Rio de Janeiro: Lumen Juris, 2011.

RÁO, Vicente. O Direito e a vida dos direitos. 5. ed. São Paulo: 1995.

REALE, Miguel. Lições preliminares do Direito. São Paulo: Saraiva, 2002.

VELOSO, Waldir de Pinho. Filosofia do Direito. São Paulo: IOB Thomson, 2005.

VEYNE, Paul. Como escreve a história: Foucault revoluciona a História. 4. ed. Brasília: Universidade de Brasília, 1998.

WOLKMER, Antônio Carlos. História do Direito no Brasil. Rio de Janeiro: Forense, 2010.

Recebido: outubro/2013. Aprovado: dezembro/2013. 


\title{
A APLICAÇÃO DA TUTELA INIBITÓRIA COLETIVA NAS CONTRATAÇÕES TEMPORÁRIAS IRREGULARES DA ADMINISTRAÇÃO PÚBLICA
}

\author{
Ana Flávia Lima Lazarino* \\ Jean Carlos Barcelos Martins ${ }^{* *}$ \\ Thiago Silva Santos***
}

Sumário: 1 Introdução; 2 Contratação temporária de excepcional interesse público; 2.1 Conceito; 2.2 Dos requisitos ensejadores da contratação temporária; 2.2.1 Dos casos excepcionais expressos em lei; 2.2.2 Da predeterminação do prazo dos contratos; 2.2.3 Da necessidade temporária de excepcional interesse público; 2.2.4 Do processo seletivo simplificado; 3 Prestação de serviços em atividades permanentes por servidores em regime excepcional: visão do STF e da doutrina; 4 A tutela inibitória coletiva na proteção do patrimônio público; 5 Considerações finais.

Resumo: Este artigo aborda a atual controvérsia sobre a contratação temporária de excepcional interesse público visando ao desempenho de atividades ordinárias na administração pública e o uso da tutela inibitória coletiva como um instrumento jurídico capaz de resguardar a aplicação adequada desse meio de contratação no âmbito dos entes políticos, enfatizando a garantia dos direitos fundamentais dos cidadãos. Tem por objetivo estudar os preceitos legais que regem as contratações temporárias pela administração pública, identificar a ocorrência desses contratos públicos e apresentar os instrumentos tutelares de proteção aos interesses coletivos pela inobservância dos ditames jurídicos nacionais aplicados ao caso. $\mathrm{O}$ trabalho tem como problemática identificar qual instrumento deve ser utilizado como inibidor de abusos pela administração pública na contratação de servidores temporários.

Palavras-chave: Tutela inibitória. Excepcional interesse público. Contratações temporárias.

\footnotetext{
* Graduada em Direito pelo Instituto Luterano de Ensino Superior (ILES/ULBRA), Itumbiara/GO.

** Mestre em Direito Público pela Universidade Federal de Uberlândia (UFU). Professor Assistente da Universidade Federal de Uberlândia (UFU), no curso de Direito da Faculdade Professor Jacy de Assis.

*** Graduado em Direito pela Universidade de Rio Verde (UniRV), Rio Verde/GO.
} 